\title{
Development of a Manually Operated Guillotine Cutter
}

\author{
${ }^{1}$ Omiogbemi Ibrahim Momoh Bello, ${ }^{2}$ Itsisor Daniel Omomoh, ${ }^{3}$ Oaikhinan Patrick Egwakhide, ${ }^{4}$ \\ Obada David Olubiyi, and ${ }^{5}$ Chira Chike Vincent
}

1, 4, 5 Department of Mechanical Engineering, Ahmadu Bello University, Zaria, Nigeria.

${ }^{2}$ Department of Mechanical Engineering, Auchi Polytechnic, Edo State.

${ }^{3}$ Department of Materials and Production Engineering, Ambrose Alli University, Edo State.

\author{
*bellistic4real@yahoo.com \\ *obadavid4@gmail.com
}

Received 21 July, 2014, Accepted 1 September, 2014, Published 08 September, 2014

\begin{abstract}
A manually operated foot leverage pedal with adjustable blades guillotine cutter was designed and constructed using locally available materials. This machine was designed to shear variety of materials with various thicknesses and sizes depending on the cutting blade capacity and the shearing angle, which cuts the materials with minimal waste and without the formation of chips and bending of the material. The machine is foot powered. It works by first clamping the material with a ram. A moving blade then comes down across a fixed blade to shear the material. The moving blade was inclined at $0.5^{\circ}$, this angle is called the rake angle, to keep the material from becoming wedged between the blades. Test carried out on mild steel shows that the machine is capable of shearing the metal sheet with maximum thickness of $0.5 \mathrm{~mm}$.
\end{abstract}

Keywords: Guillotine, Cutter, Manually, Materials.

\section{Introduction}

With the quest and search for a technological independence and breakthrough as a nation, it has become a necessity to design and fabricate engineering equipment, components and machines from locally sourced raw materials. One of such machine is a manually operated metal sheet shearing machine, otherwise known as guillotine shear (cutter).

A bench shear, also known as a lever shear, is a bench mounted shear with a compound mechanism to increase the mechanical advantage. It is usually used for cutting rough shapes out of medium sized pieces of sheet metal, but cannot do delicate work (Warg, 2001). For the small shear, it is mostly designed for a wide field of applications, light weight and easy efficient operation, yet very sturdy in construction. The cutting blades fitted are carefully and accurately ground to give easy, clean quick cuts, and free of burrs. These special features help the operators save a great deal of their energy. But some shearing machines can cut sheet bar and flat bar up to $10 \mathrm{~mm}$. It is electrically welded together to make it a sturdy stable unit capable to withstand highest stresses due to heavy duty usage. The footplates are reinforced with bracing angles so that they give firm stability to the shear. The machine is provided with section knives with sliding blades which can be adjusted by hand to make 90 cuts on angles and T-sections of different sizes as well as with openings for cutting round and square bars. (Fournier, 1990)

The machine could also be called a squaring shear, power shear, or guillotine. The machine may be foot powered (or less commonly hand powered), or mechanically or hydraulically powered. It works by first clamping the material with a ram. A moving blade then comes down across a fixed blade to shear the material. For larger shears the moving blade may be set on an angle or "rocked" in order to shear the material progressively from one side to the other; this angle is referred to as the shear angle. This decreases the amount of force required, but increases the stroke. A 5 degree shear angle decreases the force by about $20 \%$. The amount of energy used is still the same. The moving blade may also be inclined 0.5 to $2.5^{\circ}$, this angle is called the 
rake angle, to keep the material from becoming wedged between the blades, however it compromises the squareness of the edge (Degarmo, 2003). The requirement of a guillotine shear (cutter) is not restricted to big manufacturing industries but other areas such as small factories and workshops where sheets of metals are sheared into various shapes and sizes for one use or the other. The operating principles normally involve an action of shearing forces applied to the metal placed between two blades which are made of materials that can withstand the wear, abrasion and shock that result from the shearing process (3001 Series Guillotine Shears, 2008). Figure $\mathbf{1}$ below is a pictorial representation of a steel shearing machine. The design of press tools is an engineering compromise. A sharp edge, strength and durability are ideal; however, a sharp edge is not very strong or durable so blades for metal work tend to be square-edged rather than knife-edged. Typical workpiece materials include aluminum, brass, bronze, and mild steel because of their outstanding shearability ratings, however, stainless steel is not used as much due to its tendencies to work-harden (Fournier, 1990).

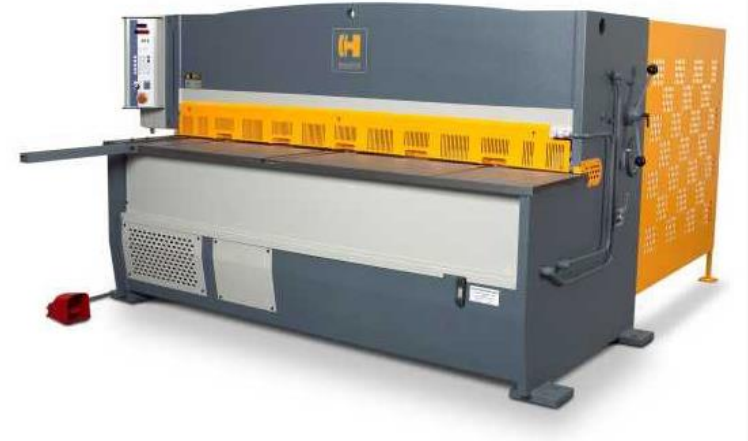

Figure 1: A steel shearing machine (Image credit: Steel Shearing Machine, retrieved 2014-07-29)

Over the years, a variety of methods have been used to obtain the desired objective of easy shearing of metals both at the local level and in the world all over. In countries such as America, Germany, Britain, Canada e.t.c, pneumatic and hydraulic methods have been in use to bring about the shearing force. This involves a hydraulic pump which is powered by a heavy duty electric motor circulating fluid energy. The energy is made to drive a piston which does work on shearing mechanism. However, these methods are quite expensive to achieve and requires a higher level of technology for their attainment.

In an effort to respond to the need of our small scale industries who cannot afford the above gigantic and very expensive model guillotine cutter, it thus become imperative to design and construct a prototype of a manually operated guillotine cutter with adjustable blade using locally available materials without sacrificing quality, economical usage and efficiency. This will go a long way in enhancing our small scale industries that are interested in the production of such machines. It will also boost our technological know-how and serve as a factor for reducing expensive importation of goods, hence appreciating the value of the Nigerian currency (naira).

\section{Material and methods}

\section{Materials Selection}

The choice of materials for the guillotine cutter depends on the particular purpose and mode of operation of the machine components. The design of engineering components is based on the materials performance requirements which are broadly divided into five categories, namely; functional requirements, processibility requirements, cost, reliability and resistance to service conditions (Myer, 2002). The questions of "what materials to be selected" for the components of the metal sheet cutting machine are: will they meet the performance requirements? Will they be available and affordable? Do they have the right aesthetic properties? In response to the above questions, the following component materials were selected for the design and fabrication of a prototype of the guillotine cutter (shear).

\section{Shearing Blade}

To avoid or minimize wear, high carbon steel material, which is a high cutting tool material, was used for the cutting blades, due to its mechanical properties of hardness, toughness, malleability e.t.c.

\section{Helical Spring}

It is required that the spring must possess the property of strength, toughness and elasticity. The selected least expensive material that satisfies this requirement was plain carbon steel.

\section{Foot leverage pedal}

The pedal constitutes part of the cutting mechanism of the force. In order to withstand the applied force, mild steel was used for the required properties of strength and hardness. 


\section{Cutter blade Support}

It is required that the cutter support has hardness, resistance to wear, and abrasion. The material used here was mild steel because of its cost effectiveness.

\section{Body frame}

The frame carries the pedal and the weight of the machine in addition to the weight which is welded in between, stands for stability purposes. The body frame was made of mild steel also.

\section{The metal sheet holder}

The metal sheet holder provides the base for the metal sheet to be placed during cutting. The impacted load on the sheet is directly absorbed and clamped by the sheet holder and it guards its edges. For this purpose, the metal sheet holder was designed to have a considerable thickness to overcome the vibration. The suitable material chosen was mild steel.

\section{Column}

The column is used like the spring to connect the cutting assembly and the pedal together. The suitable selected material for this column was mild steel.

\section{Design analysis and calculations}

The optimum design of metal sheet guillotine cutter (manually operated type), with the consideration of the above listed materials were considered to be designed for.

$\begin{array}{ll}\text { 1. } & \text { Two shearing blades (fixed and movable) } \\ \text { 2. } & \text { Two helical springs arranged in parallel } \\ \text { 3. } & \text { A foot leverage pedal } \\ \text { 4. } & \text { A shaft } \\ \text { 5. } & \text { Two columns; } \\ \text { 6. } & \text { Eight hexagonal head bolts and nuts } \\ \text { 7. } & \text { Body supporting arms } \\ \text { 8. } & \text { Two metal sheet guards } \\ \text { 9. } & \text { Metal sheet holder for cutting, and } \\ \text { 10. } & \text { A frame }\end{array}$

For the purpose of this paper the design analysis and calculations of the two shearing blades will be discussed.

\section{The Shearing Blades Design Analysis}

Shearing is the mechanical cutting of materials in sheet or plates form without the formation of chips or use of burning or melting (Myer, 2002). In considering the major properties required in shearing blade, which are: hardness, strength, impact, toughness or high mechanical vibrations at elevated temperature and over a long period (tool life), carbon tool steel is used for the design of the shearing blades as compared with the other shearing tools such as alloy tool steels, high speed steels, cemented carbides, ceramic-tools, diamonds and abrasives as shown in Table 1 (Ibhadode, 2001), since the objective is to select the least expensive material that satisfies the requirements.

A punch (or moving blade) is used to push the workpiece against the die (or fixed blade), which is fixed. Usually the clearance between the two is 5 to $40 \%$ of the thickness of the material, but dependent on the material (Todd et al, 1994). Clearance is defined as the separation between the blades, measured at the point where the cutting action takes place and perpendicular to the direction of blade movement. It affects the finish of the cut (burr) and the machine's power consumption. This causes the material to experience highly localized shear stresses between the punch and die. The material will then fail when the punch has moved 15 to $60 \%$ the thickness of the material, because the shear stresses are greater than the shear strength of the material and the remainder of the material is torn (Wick and Veilleux, 1984).

Table 1: Values of hardness and maximum cutting temperature for various shearing blades materials (Ibhadode , 2001)

\begin{tabular}{|c|c|c|c|}
\hline & Materials & $\begin{array}{l}\text { Hardness } \\
\text { values }\end{array}$ & $\begin{array}{l}\text { Maximum cutting } \\
\text { temperature }\end{array}$ \\
\hline 1 & $\begin{array}{l}\text { Carbon tool } \\
\text { steel }\end{array}$ & $58-64 \mathrm{RC}$ & $200-250^{\circ} \mathrm{C}$ \\
\hline $\begin{array}{l}2 \\
3\end{array}$ & $\begin{array}{l}\text { Alloy tool steels } \\
\text { High speed steel } \\
\text { (HSS) }\end{array}$ & $\begin{array}{l}68-77 \mathrm{RC} \\
62-65 \mathrm{RC}\end{array}$ & $\begin{array}{l}250-300^{\circ} \mathrm{C} \\
600^{\circ} \mathrm{C}\end{array}$ \\
\hline 4 & $\begin{array}{l}\text { Cemented car- } \\
\text { bides }\end{array}$ & $87-92$ RA & $800-900^{\circ} \mathrm{C}$ \\
\hline $\begin{array}{l}5 \\
6\end{array}$ & $\begin{array}{l}\text { Ceramic tool } \\
\text { diamond }\end{array}$ & $89-95$ RA & $\begin{array}{l}\text { About } 1200^{\circ} \mathrm{C} \\
\text { About } 1500^{\circ} \mathrm{C}\end{array}$ \\
\hline
\end{tabular}

\section{The Shearing Blades Design Calculations.}

The design for the shearing blades was as adopted by (Khumi and Gupta, 2006).

$$
\begin{aligned}
& \propto=\text { Shearing angle } \\
& t_{m}=\text { metal sheet thickness (maximum). } \\
& I_{s 2}=\text { maximum shearing length } \\
& f_{s 1}=F_{1}+F_{2}=\text { maximum shearing force }
\end{aligned}
$$


Figure 2 shows the metal sheet shearing operation. A punch (or moving blade) is used to push the workpiece against the die (or fixed blade), which is fixed. F1 and F2 are the shearing forces.

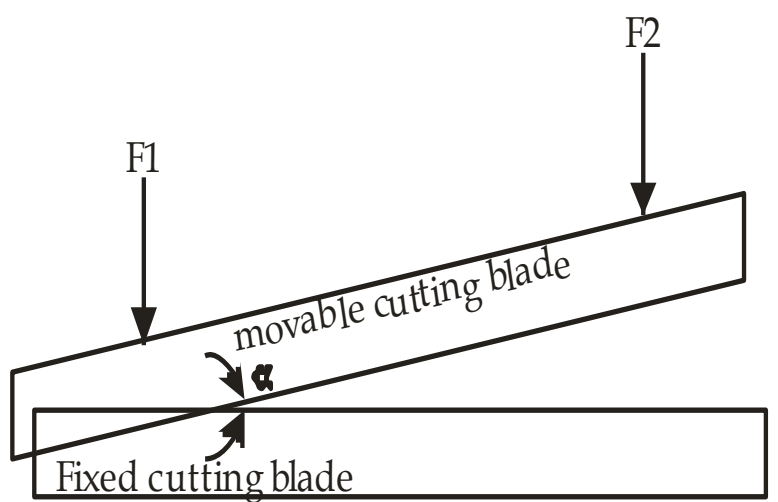

Figure 2: The metal sheet shearing operation (Myer Kutz, 2002).

(a) The shearing angle $\propto=\operatorname{Sin}^{-1} \underline{t_{m}}$

$$
\text { Ls2 } \ldots . . .(1)
$$

Where $t_{m}=$ maximum metal sheet thickness $=$ $0.5 \mathrm{~mm}$

$\mathrm{Ls}_{2}=$ maximum shearing length $=85 \% \times$ blade length (Lb) (Khumi and Gupta, 2006).

i.e $L b=570 \mathrm{~mm}, \mathrm{~L}_{\mathrm{s} 2}=\quad 85 \% \times 570=484.5 \mathrm{~mm}$

$L_{s 1}=$ minimum shearing length $=80 \% \times$ blade length (Khumi and Gupta, 2006)

$\mathrm{L}_{\mathrm{s} 1}=80 \% \times 570=456 \mathrm{~mm}$

Therefore,

$$
\begin{aligned}
& \propto \quad=\sin ^{-1} \underline{0.5}=\sin -1(0.00103) \\
& 484.5 \\
& \propto \quad=\underline{\mathbf{0 . 0 5 ^ { \circ }}}
\end{aligned}
$$

To obtain the weight $(\mathrm{Wb})$ of the shearing blade, applying

$W_{b}=m_{b} \quad x g$.

$v_{b}=m_{b} / e_{b} m_{b}=v_{b} \times e_{b}$

where,

$\mathrm{e}_{b}=$ shearing blade density (carbon steel) $=7.83 \mathrm{x}$ $10^{3} \mathrm{~kg} / \mathrm{m}^{3}$

$g=$ Acceleration due to gravity $=9.8 \mathrm{~m} / \mathrm{s}^{2}$ $\mathrm{m}_{\mathrm{b}}=$ Mass of the shearing blade $=\mathrm{v}_{\mathrm{b}} \times \mathrm{e}_{\mathrm{b}}$

$\mathrm{v}_{\mathrm{b}}=\mathrm{l}_{\mathrm{b}} \times \mathrm{b}_{\mathrm{b}} \times \mathrm{t}_{\mathrm{b}}$

$\mathrm{l} b=$ blade length $=570 \mathrm{~mm}$

$b_{b}=$ blade width $=50 \mathrm{~mm}$

$\mathrm{t}_{\mathrm{b}}=$ blade thickness $=7 \mathrm{~mm}$

$v_{b}=570 \times 50 \times 7=199.5 \times 10^{3} \mathrm{~mm}^{3}=1.995 \times 10^{-4} \mathrm{~m}^{3}$

$\mathrm{m}_{\mathrm{b}}=1.996 \times 10^{-4} \times 7.83 \times 10^{3}=15.62 \times 10^{-1}=$ $1.56 \mathrm{~kg}$

$\mathrm{w}_{\mathrm{b}}=\mathrm{mg}=1.56 \times 9.8=15.29 \mathrm{~N}$

since the blades are two,then

The total weight $w_{b}=2 \times 15.2=\underline{\mathbf{3 0 . 4 N}}$.

\section{Machine efficiency}

The efficiency of the guillotine cutter is given by $(\mathrm{MA} / \mathrm{VR}) \times 100$.....

Where;

MA is mechanical advantage

$V R$ is velocity ratio

$M A=\operatorname{Load} /$ Effort $=L_{1} / \mathrm{b}$

Where; $L_{1}=$ weight of the material part to be cut $\left(W p_{1}\right)$

$\mathrm{W}_{\mathrm{m}}=\mathrm{LM} \mathrm{mg}$

$g=$ acceleration due to be gravity $=9.8 \mathrm{~m} / \mathrm{s}^{2}$

$\mathrm{M}_{\mathrm{m}}=\mathrm{V}_{\mathrm{me}}$

$V_{m}=$ Volume of the material part to be cut

$\mathrm{V}_{\mathrm{m}}=\mathrm{LS}_{2} \times \mathrm{t}_{\mathrm{m}} \times \mathrm{b}_{\mathrm{m}}$

Where:

$\mathrm{LS}_{2}=$ Maximum shearing length $=484.5 \mathrm{~mm}$

$\mathrm{T}_{\mathrm{m}}=$ Maximum metal sheet thickness $=0.5 \mathrm{~mm}$

Let the breadth $\left(b_{m}\right)$ be unity

$V_{m}=484.5 \times 10^{-3} \times 0.3 \times 10^{-3} \times 1 \times 10^{-3}$

$V_{\mathrm{m}}=2.4335 \times 10^{-7} \mathrm{~m}^{3}$

$\mathrm{e}=$ density of material to be cut $=7.83 \times 10^{3} \mathrm{~kg} / \mathrm{m}^{3}$

$M_{m}=V_{m e}=2.4225 \times 10^{-7} \times 7.83 \times 10^{3}$ 
$\mathrm{Mm}=1.897 \times 10^{-3} \mathrm{~kg}$

$\mathrm{W}=\mathrm{M}_{\mathrm{mg}}=1.897 \times 10^{-3} \times 9.8=0.0186$

$\therefore \mathrm{L}=\mathrm{W}=0.019 \mathrm{~N}$

$M A=L / E$

Where,

$E$ = expected axial load or force to cut the metal sheet which is $937.72 \mathrm{~N}$

$M A=L / E=0.019 / 937.72=\underline{\mathbf{2 . 0 2 6} \times 10^{-5}}$

For $V R=D_{E} / D_{L}$

Recall that from the design, $D E=0.011 \mathrm{~mm}$ Where,

$\mathrm{DE}=$ Distance moved by effort

DL- Distance moved by load $=\mathrm{Ls} 2=484.5 \mathrm{~mm}$

$\mathrm{VR}=0.011 / 484.5=\underline{\mathbf{2 . 2 7 0 \times 1 0 ^ { - 5 }}}$

Hence, Efficiency $=(\mathrm{MA} / \mathrm{VR}) \times 100 \%=$ $\left(2.026 \times 10^{-5}\right) /\left(2.270 \times 10^{-5}\right) \times 100 \%$

\section{:. Efficiency $=\underline{\mathbf{8 9} \%}$}

\section{Results and discussion}

The completion of this prototype design proves that imported machines can be locally fabricated. The machine is so designed that it could be easily operated and has a high degree of safety. Test carried out shows that the machine is capable of shearing mild steel metal sheet with maximum thickness of $0.5 \mathrm{~mm}$. From calculations, the efficiency of the machine was found to be $89 \%$. Figure 3 shows an assembly of the developed guillotine cutter;

From figure 3, the shearing blade (fixed blade and movable blade) was to avoid or minimize wear. It is required that the spring must possess the property of strength, toughness and elasticity. The foot pedal constitutes part of the cutting mechanism of the force. The frame carries the pedal and the weight of the machine in addition to the weight which is welded in between stands for stability purposes. The metal sheet holder provides the base for the metal sheet to be placed during cutting. The impacted load on the sheet is directly absorbed and clamped by the sheet holder and it guards its edges. For this purpose, the metal sheet holder was designed to have a considerable thickness to overcome the vibration.
The column is used like the spring to connect the cutting assembly and the pedal together

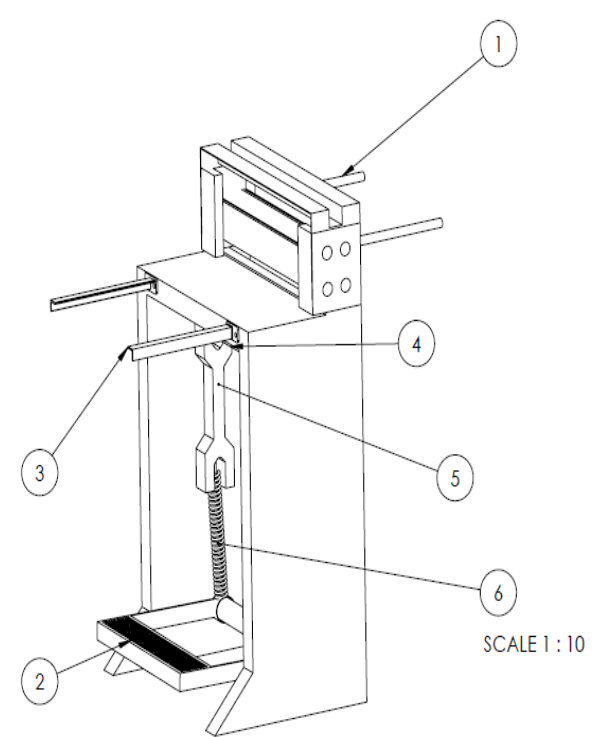

Figure 3: An assembly drawing of the Guillotine cutter, (1) Metal sheet guard; (2) Pedal; (3) Suporting arm; (4) Fixed blade; (5) Column and (6) Spring.

\section{Maintenance}

The following activities should be observed to maintain the machine.

1. Attempt should not be made to cut materials with thickness that is not designed for.

2. The spring should be checked periodically to see if there is any failure due to buckling and replace it if any.

3. All bolts and nuts should be well tightened before any cutting operation.

Lubrication should always be applied to all movable parts, such as the shaft component.

\section{Conclusion}

In an effort to respond to the need of our small scale industries who cannot afford the gigantic and very expensive model guillotine cutter, it thus becomes imperative to design and construct a prototype of a manually operated guillotine cutter with adjustable blade using locally available materials without sacrificing quality, economical usage and efficiency. This will go a long way in enhancing our small scale industries that are interested in the production of such machines. It will also boost our technological know-how and militate against expensive importation of goods, hence appreciating the value of the Nigerian currency (naira). 


\section{References}

Ibhadode A.A.O. (2001). Introduction to Manufacturing technology. Ambik Press, Ugbowo, Benin City. Pp 354-357, 496.

Degarmo, E. Paul; Black, J T.; Kohser, Ronald A. (2003), Materials and Processes in Manufacturing (9th ed.), Wiley,ISBN 0-471-65653-4.

Fournier S. (1990), Metal fabricator's handbook, HPBooks, p. 28, ISBN 978-0-89586-870-1

Khumi R.S. and Gupta J.K. (2006). Machine Design. Eurasia Publishing House (PVT) Ltd. Pp 1,21, 566-567, 824, 828-830, 833, 853

Myer K. (2002). Hand Book of Materials Selection. Pp 944-955.21, 566-567, 824, 828-830, 833, 853.
Steel Shearing Machine, http://en.wikipedia.org/wiki /Shear_(sheet_metal),retrieved 2011-07-29.

Todd, Robert H.; Allen, Dell K.; Alting, Leo (1994), Manufacturing Processes Reference Guide, Industrial Press Inc., ISBN 0-8311-3049-0

Warg, Pauline (2006), Making Metal Beads: Techniques, Projects, Inspiration, Sterling Publishing Company, p. 12, ISBN 978-1-57990-712-9..

Wick C. and Veilleux R.F. (1984), Tool and Manufacturing Engineers Handbook: Forming (4th ed.), SME,ISBN 978-0-87263-135-9.

"3001 Series Guillotine Shears" available at http://www.accucuter.com/3001.htm, Retrieved on 2nd August, 2008. 